\title{
КАРДИОХИРУРГИЯ
}

УДК 616.12-089,616.126

П. П. Яблонский ${ }^{1,2}$, С. Чеботарь ${ }^{2}$, И. Тудорахе ${ }^{2}$, А. Хаверих ${ }^{2}$

ТКАНЕВЫЕ МАТРИЦЫ КЛАПАНОВ СЕРДЦА: СОСТОЯНИЕ ПРОБЛЕМЫ И ПЕРСПЕКТИВЫ

${ }^{1}$ Санкт-Петербургский государственный университет, Российская Федерация, 199034, Санкт-Петербург, Университетская наб., 7-9

2 Клиника кардиоторакальной, сосудистой хирургии и трансплантации Медицинского университета Ганновера, Carl-Neuberg Str., 1, OE 6210, 30625, Hannover, Germany

Первые успешные протезирования аортального и митрального клапанов сердца были выполнены в 1960 г. соответственно D. Harken и N. Braunwald. B обоих случаях использовались механические протезы, однако спустя всего 10 лет M. Ionescu впервые имплантировал первый биологический клапан человеку. В ходе эволюции биологических клапанных протезов хирургами использовались свиные аортальные, ксеноперикардиальные протезы и человеческие аллографты (свежие и криосохраненные), а в последние полтора десятилетия на вооружение были взяты тканевая инженерия и направленная регенерация тканей. В настоящей статье описаны основные проблемы этой области, проведена сравнительная характеристика различных методик децеллюляризации полулунных клапанов, а также перспективы использования тканевой инженерии для создания атриовентрикулярных клапанных заменителей. Библиогр. 73 назв. Ил. 1.

Ключевые слова: тканевая инженерия, направленная регенерация, децеллюляризация, децеллюляризированный клапан сердца, тканевая матрица.

\section{HEART VALVE MATRICES: STATE OF THE ART AND PERSPECTIVES}

\section{P. P. Iablonskii ${ }^{1,2}$, S. Cebotari ${ }^{2}$, I. Tudorache ${ }^{2}$, A. Haverich ${ }^{2}$}

${ }^{1}$ St. Petersburg State University, 7-9, Universitetskaya nab., St. Petersburg, 199034, Russian Federation

2 Hannover Medical School, Department of Cardiothoracic, Transplantation and Vascular Surgery, Carl-Neuberg Str., 1, 30625, Hannover OE 6210

The first successful aortic and mitral valve replacement was performed, respectively, by D. Harken and N. Braunwald in 1960. Both used mechanical grafts, but 10 years later M. Ionescu implanted a biological valve substitute in humans. As biological valve grafts evolved, multiple sources were used: porcine aortic valves, xenopericardial substitutes, and, most recently, tissue engineered allografts, reseeded by means of guided repopulation. The present work describes the major challenges of these methods, analyses different decellularization approaches used for semilunar valves, and future possibilities for tissue engineering to be applied in humans, such as creation of atrioventricular valve substitutes. Refs 73. Figure 1.

Keywords: tissue engineering, guided regeneration, decellularization, decellularized heart valve, tissue matrix.

(C) Санкт-Петербургский государственный университет, 2016 


\section{Введение}

Протезирование клапанов сердца - операция, имеющая долгую историю. Первые успешные ортотопические вмешательства такого типа были выполнены в 1960 г. - D. Harken на аортальном клапане [1] и N. Braunwald на митральном клапане [2]. В обоих случаях использовались механические протезы, однако параллельно шли разработки биологических искусственных клапанов сердца (БИКС), и спустя всего 10 лет M.Ionescu имплантировал ксеноперикардиальный клапан человеку [3]. В ходе эволюции БИКС хирурги использовали свиные аортальные, ксеноперикардиальные протезы и человеческие аллографты (свежие и криосохраненные), а в последние полтора десятилетия на вооружение были взяты тканевая инженерия и направленная регенерация тканей. В настоящей статье описаны основные проблемы и достижения в этой области, а также перспективы создания новых типов клапанных протезов.

\section{Тканевая инженерия в сердечно-сосудистой хирургии}

В последние два десятилетия в разработке биологических клапанных протезов появились новые методики, объединенные термином «тканевая инженерия» [4]. Основная идея тканевой инженерии заключается в использовании биологических или синтетических матриц с формой и/или функциями требуемого органа для последующего замещения поврежденной ткани. Применительно к протезированию сердечных клапанов тканевая инженерия представляет грядущие альтернативные источники создания жизнеспособных и биологически активных заменителей, встраивающихся в организм реципиента [4]. Существуют две разные концепции: клапанные протезы либо засеиваются клетками in vitro до операции (собственно тканевая инженерия) [5-7], либо имплантируются бесклеточные матрицы, призванные служить субстратом для заселения клетками in vivo (направленная регенерация) [8-10]. Можно предположить, что жизнеспособные протезы, созданные с помощью тканевой инженерии, будут обеспечивать полную биосовместимость, атромбогенность, атератогенность и долговечность, близкие к природным биомеханические показатели и, более того, будут обладать нормальной биологической способностью к росту. Тканево-инженерные клапаны необходимы детям и молодым взрослым, поскольку у больных этих возрастных групп результаты протезирования клапанов не так хороши, как у больных старшего возраста $[11,12]$.

Необходимо сказать, что все приведенные ниже методики относятся преимущественно к легочному и аортальному клапанам. В доступной литературе удалось обнаружить только две работы, описывающие попытки создания атриовентрикулярного клапана и его элементов, но обе были посвящены синтетическим матрицам $[13,14]$.

\section{Децеллюляризированные матрицы полулунных сердечных клапанов}

Любая биологическая матрица, и в этом заключается ее отличие от синтетической, основана на донорском материале - применительно к кардиохирургии это сердечные клапаны, заготовленные после смерти донора. Для создания из свежего 
клапана матрицы используется процесс децеллюляризации, впервые предложенный S. Badylak [15]. Описаны различные методы создания абсолютно бесклеточных аллогенных и ксеногенных матриц с помощью удаления клеточных компонентов, которые, как принято думать, вызывают остаточный иммунный ответ и последующую дегенерацию [16]. Методики децеллюляризации могут быть основаны на механическом, ферментативном, детергентном воздействиях или их комбинации для удаления клеток и сохранении матрицы, составленной преимущественно из внеклеточных компонентов. Для разных тканей эффективными могут быть разные методики децеллюляризации - это зависит от множества факторов: клеточности ткани, плотности, содержания липидов, толщины и т. п. Кроме того, любой метод в какой-то степени повреждает внеклеточный матрикс и вызывает определенное нарушение его микроструктуры, поэтому задачей децеллюляризации является не только максимально полное удаление несущих антигены клеток, но и минимизация ущерба, наносимого матриксу. Далее рассмотрены основные агенты, использующиеся для децеллюляризации различных тканей.

\section{Химические агенты}

Кислоты и основания вызывают или катализируют гидролиз биомолекул. Перуксусная кислота - известное дезинфицирующее вещество, может использоваться и в качестве децеллюляризирующего агента, эффективно удаляя остатки нуклеиновых кислот, практически не воздействуя на матрикс $[17,18]$. Уксусная кислота повреждает и вымывает коллаген, уменьшая прочность матрикса, но не воздействует на сульфатированные гликозаминогликаны [19]. Щелочи воздействуют на ткани чересчур жестко, полностью удаляя из тканей факторы роста и значительно снижая их механическую прочность [20]. Основным механизмом, приводящим к ухудшению механических свойств в результате воздействия, например, гидроксида натрия, является расщепление коллагеновых волокон и поперечных сшивок между ними [21].

Гипо- и гипертонические растворы приводят к диссоциации комплексов ДНКбелок [22]. Гипотонические растворы также вызывают лизис клеток за счет обычного осмотического эффекта с минимальными изменениями молекул и общего строения внеклеточного матрикса [23]. Для максимально полного проявления осмотического эффекта часто прибегают к поочередному промыванию ткани в гипер- и гипотоническом растворах. Кроме того, этот метод помогает удалить из ткани фрагменты клеток, оставшиеся после лизиса, вызванного другими агентами.

Детергенты. Ионные, неионные и цвиттерионные детергенты эффективно растворяют клеточную мембрану и вызывают диссоциацию ДНК и белков, удаляя клеточный материал из ткани [24]. В то же время они способны повреждать и диссоциировать белки внеклеточного матрикса, степень вымывания белков внеклеточного матрикса и ДНК возрастает пропорционально времени экспозиции образца раствору [25] и отличается в зависимости от органа, ткани и возраста донора [26]. Комбинирование нескольких детергентов увеличивает степень повреждения матрикса [27], но также способствует более полному удалению самих детергентов из него после окончания децеллюляризации [28-30]. Так, тритон X-100 эффективен в отноше- 
нии сравнительно толстых тканей, таких как клапанные кондуиты, где ферментативные и осмотические методики оказываются неэффективными, а сопутствующее повреждение внеклеточного матрикса сопровождается также и менее выраженным иммунным ответом реципиента in vivo, что говорит о высокой эффективности этого детергента [31]. Додецилсульфат натрия (SDS) считается более эффективным по сравнению с тритоном X-100 в отношении удаления ядер из плотных тканей при сохранении ее механических свойств [26, 32]. Однако SDS вызывает микроструктурные повреждения межклеточного вещества $[33,34]$ и удаляет из ткани факторы роста [20]. В то же время тритон X-100 эффективнее ионных детергентов для удаления жирорастворимых компонентов ткани [29]. Цвиттерионные детергенты, такие как 3-[(3-холамидопропил) диметриламмонио]-1-пропансульфонат (CHAPS), лучше всего проявили себя в децеллюляризации тонких тканей, например легочной [35], но оказались неэффективны в отношении толстых образцов [36, 37]. В 2002 г. C. Booth et al. при сравнении различных методик децеллюляризации показали, что только дезоксихолат и додецилсульфат натрия способны полностью удалить клетки из ткани без видимого повреждения микростуктуры внеклеточного матрикса, включая коллагены, эластин и гликозаминогликаны [38]. В то же время E. Rieder et al. предположили, что SDS способен разрушать трехспиральную структуру коллагена и тем самым повреждать структуру ткани [28].

Важной особенностью детергентной децеллюляризации является остаточная токсичность этих агентов, особенно SDS, обусловленная глубоким проникновением их в толщу ткани [39]. Эта особенность требует тщательного промывания образцов после окончания процесса - не менее шести 12-часовых циклов [29].

Cnupmbl, например глицерол, вызывают дегидратацию и лизис клеток [40]. Он способен удалять фосфолипиды из клапанных кондуитов, усиливающие кальцификацию протеза $[41,42]$. Кроме того, изопропанол, этанол и метанол показали себя более эффективными для быстрого удаления жиров, чем липаза $[43,44]$. Однако требуется тщательный подбор концентрации и времени экспозиции, поскольку спирты способны фиксировать ткани, осаждать белки и повреждать микроструктуру внеклеточного матрикса $[21,45,46]$.

Другие растворители - ацетон, трибутил фосфат - также повреждают структуру внеклеточного вещества, а ацетон вызывает ее фиксацию, одновременно увеличивая механическую прочность $[21,32,45,46]$.

\section{Биологические агенты}

Ферменты, используемые для децеллюляризации, в литературе описаны в большом количестве: это нуклеазы, трипсин, коллагеназа, липаза, диспаза, термолизин и $а$-галактозидаза. Однако полное удаление клеток только с помощью ферментативных методик затруднено, а остатки активных ферментов препятствуют рецеллюляризации [47]. Показано, что эндонуклеазы эффективнее экзонуклеаза удаляют ДНК, поскольку разрезают ее на более короткие фрагменты [35]. Для обработки тканей наиболее часто используется трипсин - сериновая протеаза, воздействующая также и на коллагены, что вызывает более выраженное снижение механической прочности ткани, чем детергентная децеллюляризация $[35,48,49]$. 
С другой стороны, он значительно меньше влияет на гликозаминогликаны. Еще один вариант использования трипсина - для первичного «вскрытия» ткани, облегчающего проникновение внутрь других децеллюляризирующих агентов, что улучшает конечный результат обработки [50]. Липазы, как было показано, самостоятельно не способны удалить все жиры, поэтому используются только как одна их составляющих сложных протоколов $[43,44]$. Диспаза - нейтральная протеаза - позволяет более эффективно, чем трипсин, удалять клеточные компоненты из ткани, одновременно сильнее повреждая матрикс, но при этом способствуя ускоренной репопуляции [40]. Также трипсин и диспаза используются в качестве дополнения к детергентам при децеллюляризации сложных тканей [25]. Термолизин в качестве единственного агента может удалять клетки только с поверхности ткани, поэтому его применение ограничено [51]. Высокоспецифичный фермент a-галактозидаза применяется как компонент методики для децеллюляризации ксеногенной ткани и отвечает за удаление эпитопа $\alpha-G a l[23,52]$.

Хелатирующие вещества, такие как этилендиаминтетраацетат (ЭДТА) и этиленгликольтетраацетат (ЭГТА), диссоциируют клетки от внеклеточного матрикса, секвестрируя ионы металлов [53]. Вероятнее всего, этот же механизм ответствен за нарушение межбелковых связей [54]. Сами по себе хелатирующие агенты не могут вызвать даже поверхностную децеллюляризацию, поэтому используются в комбинации с трипсином $[31,50,55,56]$ или детергентами $[20,31,50,56,57]$. Необычный метод был предложен A. R. Gillies et al.: они использовали латрункулин, природный токсин морских губок, в сочетании с осмотическим шоком и ДНазой для децеллюляризации скелетной мышцы. Было показано, что эта комбинация эффективнее удаляет ДНК, внутриклеточные белки и меньше влияет на гликозаминокликаны, чем ферментативные и детергентные методики, а также не приводит к ухудшению механических характеристик [58].

\section{Физические факторы}

Особый температурный режим - поочередное замораживание и оттаивание ткани - приводит к разрушению клеток в тканях и органах, но препятствует удалению клеточного детрита из матрикса, хотя даже одиночный цикл замораживание-оттаивание может снизить последующую лейкоцитарную инфильтрацию сосудистого аллографта [57]. Многократное же повторение цикла не приводит к значимой потере белков, но отрицательно сказывается на механических свойствах матрикса [59, 40, 43, 51, 60].

Нетермическая необратимая электропорация (NTIRE) - также один из подходов к децеллюляризации тканей. Электрические импульсы микросекундной продолжительности проделывают мельчайшие поры в клеточных мембранах, нарушая их потенциал [61]. Эксперименты in vivo на сонной артерии крысы показали, что остатки клеток после воздействия электрических импульсов в течение трех дней вымываются из сосудистой стенки, оставляя бесклеточную ткань [62]. 


\section{Донорский материал для тканевой инженерии}

Отдельной проблемой является поиск донорского материала для создания клапанных матриц. Наилучшими с точки зрения массового производства являются ксеногенные тканевые матрицы, а полное удаление клеток из ксеногенной ткани должно свести к минимуму ее антигенные свойства. Однако E. Reider et al. отметили, что децеллюляризированные свиные матрицы сохраняют выраженную способность привлекать моноциты в сравнении с человеческими матрицами [63].

Хотя эксперименты на животных с имплантацией децеллюляризированных ксеногенных матриц были многообещающими, клиническое применение таких клапанов было неудачным. P. Simon et al. использовали SynerGraft - децеллюляризированный свиной клапан - для реконструкции выводного тракта правого желудочка у детей и продемонстрировали высокую частоту ранней дисфункции [64]. Необходимо отметить некорректность выбранной модели - невозможна экстраполяция скорости деградации и гемодинамического подведения клапанного заменителя в легочной позиции на его функционирование в аортальной, в частности, из-за различных величин сдвигового напряжения, воспринимаемых протезом: биологические клапаны в легочной позиции служат дольше, чем в аортальной, а после выполнения операции Росса клапан легочной артерии в аортальной позиции деградирует существенно быстрее, чем нативный аортальный [65]. Кроме того, ксеногенную модель «от свиньи к овце» нельзя считать эквивалентной клинической ситуации «от свиньи к человеку», поскольку в последнем случае сверхострое отторжение вызывает как минимум один общий для свиньи и овцы, но чужеродный для человека антиген - a-GAL [66]. Поэтому, к сожалению, недостаточность децеллюляризации (технология предполагала гипотонический лизис клеток и обработку ДНазой) проявилась только на клиническом этапе - больные погибали из-за быстрой дегенерации и разрыва донорской части стенки аорты вследствие острого воспаления [64]. В настоящий момент проблема ксенотрансплантации попрежнему не решена $[67,52]$.

Группа W. Konnertz представила многообещающие результаты доклинических испытаний, а также данные, полученные после имплантации ксенографтов на модели растущей овцы. Тем не менее клиническое применение децеллюляризированных свиных клапанных протезов «Matrix Р» для замещения клапана легочной артерии у детей и молодых взрослых оказалось неудачным [68-70]. Вероятно, человеческий иммунный ответ на нефиксированную ксеногенную ткань играл решающую роль в дегенерации клапана. Возможно, несоответствие хороших результатов доклинических испытаний на овцах и неудовлетворительных клинических результатов объясняется выбором неправильной экспериментальной модели животного. Трансплантация нефиксированной децеллюляризированной свиной ткани приматам могла бы быть более адекватной и репрезентативной моделью человеческой системы и лучше отражать механизмы иммунологически опосредованного разрушения ксеногенной ткани.

Напротив, использование децеллюляризированных матриц, основанных на человеческих тканях, продемонстрировало удовлетворительные ранние и среднесрочные результаты. F. Da Costa et al. сообщили о значимом снижении иммунного ответа на децеллюляризированные человеческие аллографты в сравнении с крио- 
консервированными клапанами, а также об их нормальном функционировании in vivo вплоть до 19 месяцев наблюдения [71].

B 2006 г. A. Lichtenberg et al. сообщили о первом клиническом опыте использования клапанов, созданных с помощью децеллюляризации с последующим заселением эндотелиальными клетками реципиентов, и о среднеотдаленных (3,5 года) результатах их имплантации больным детского возраста. Эти клапаны в течение упомянутого срока наблюдения не имели признаков стеноза, дегенерации, нарастания недостаточности, утолщения створок или снижения их подвижности. Также было зафиксировано постепенное увеличение диаметра фиброзного кольца клапана одновременно с уменьшением послеоперационной регургитации по мере нормального роста пациента. Этот феномен был интерпретирован как нормальный физиологический рост клапана, созданного с применением тканевой инженерии и направленной регенерации $[6,72]$. Опыт этой группы в имплантации децеллюляризированных легочных и аортальных гомографтов детям и молодым взрослым говорит о лучших показателях этих клапанов по сравнению с криоконсервированными гомографтами и фиксированными в глутаральдегиде ксенографтами. В результате имплантации этих клапанов юным пациентам были отмечены повышенная долговечность и способность к адаптивному росту. Эти клапаны отличались лучшими показателями и более высокой выживаемостью без повторных вмешательств [72].

\section{Децеллюляризированная матрица атриовентрикулярного клапана}

В 2015 г. нами впервые в мире была получена тканевая матрица на основе митрального клапана, созданная на модели овцы [73] (рисунок). В работе предложен принципиально новый раствор для децеллюляризации, включавший в себя, помимо детергентов (натрия додецилсульфат и натрия дезоксихолат), восстанавливающий агент - $\beta$-меркаптоэтанол. Гистологический анализ показал сохранение строения хорд и характерной четырехслойной структуры створок митрального клапана при полном отсутствии клеточных элементов. Иммунофлюоресцентный анализ

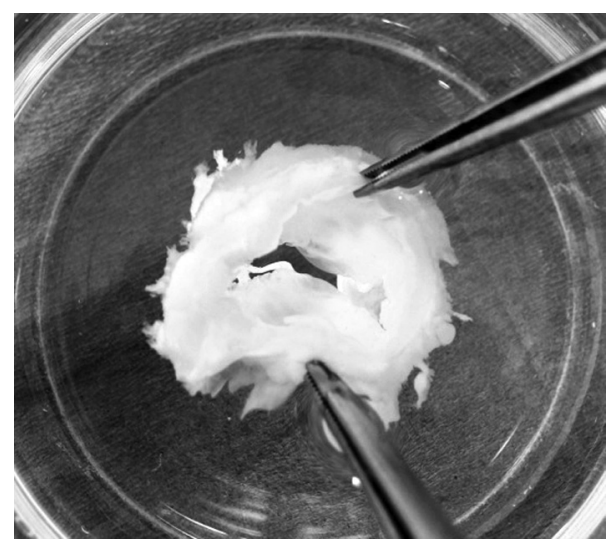

Децеллюляризированная тканевая матрица на основе овечьего митрального аллографта 
показал сохранение волокон коллагена I и IV типа, а также полную элиминацию не только ДНК, но и эпитопа $\alpha$-GAL, выбранного как мембранный (внеклеточный) маркер децеллюляризации. Кроме того, полученная матрица продемонстрировала механические свойства, сопоставимые с нативным клапаном, а также высокий потенциал к репопуляции аллогенными эндотелиальными клетками. В ходе хирургического эксперимента, целью которого была оценка макро- и микроструктурных изменений матрицы in vivo в ортотопической позиции, были показаны отсутствие кальцификации по истечении 6 месяцев, а также начавшаяся репопуляция поверхности эндотелиальными клетками реципиента.

\section{Заключение}

Таким образом, тканевая инженерия в последние годы перестала быть одной из дисциплин фундаментальной науки и перешла в раздел трансляционной медицины. Очевидно, что наиболее успешные заменители клапанов сердца, созданные с применением методов тканевой инженерии, позволяют существенно улучшить отдаленные результаты протезирования, в первую очередь у молодых больных, не требуя антикоагулянтной терапии. Однако остаются и нерешенные проблемы нехватка донорского материала и связанная с этим необходимость создания метода обработки тканей, делающего возможным ксеногенную трансплантацию. По-видимому, именно на эти проблемы будут направлены усилия исследователей в ближайшие годы.

\section{References}

1. Harken D., Soroff H., Taylor W. Partial and complete prostheses in aortic insufficiency. J. Thorac. Cardiovasc. Surg., 1960, vol. 40, p. 744.

2. Braunwald N.S., Morrow A. G. Prosthetic reconstruction of the mitral valve. Prog. Cardiovasc. Dis., 1963, vol. 5, no. 4, pp. 313-328.

3. Ionescu M. I. et al. Heart valve replacement with the Ionescu-Shiley pericardial xenograft. J. Thorac. Cardiovasc. Surg., 1977, vol. 73, no. 1, pp.31-42.

4. Fuchs J. R., Nasseri B. A., Vacanti J.P. Tissue engineering: A 21st century solution to surgical reconstruction. Ann. Thorac. Surg., 2001, vol. 72, no. 01, pp. 577-591.

5. Lichtenberg A. et al. Biological scaffolds for heart valve tissue engineering. Methods Mol. Med., 2007, vol. 140, no. 2, pp. 309-317.

6. Lichtenberg A. et al. Flow-dependent re-endothelialization of tissue-engineered heart valves. J. Heart Valve Dis., 2006, vol. 15, pp. 287-293; discussion 293-294.

7. Shinoka T. et al. Tissue engineering heart valves: Valve leaflet replacement study in a lamb model. Ann. Thorac. Surg., 1995, vol.60, pp.S513-S516.

8. Dohmen P. M. et al. Results of a decellularized porcine heart valve implanted into the juvenile sheep model. Heart Surg. Forum, 2005, vol. 8, no. 2, pp.72-76.

9. Dohmen P. M. et al. Histological evaluation of tissue-engineered heart valves implanted in the juvenile sheep model: is there a need for in-vitro seeding? J. Heart Valve Dis,. 2006, vol. 15, no. 6, pp. 823-829.

10. O'Brien M.F. et al. The SynerGraft valve: a new acellular (nonglutaraldehyde-fixed) tissue heart valve for autologous recellularization first experimental studies before clinical implantation. Semin. Thorac. Cardiovasc. Surg., 1999, vol. 11, no. 4 Suppl. 1, pp. 194-200.

11. Erez E. et al. Mitral valve replacement in children. J. Heart Valve Dis., 2003, vol. 12, no. July 2000, pp. $25-30$.

12. Mendelson K., Schoen F.J. Heart valve tissue engineering: Concepts, approaches, progress, and challenges. Ann. Biomed. Eng., 2006, vol. 34, no. 12, pp. 1799-1819. 
13. Shi Y., Vesely I. Characterization of statically loaded tissue-engineered mitral valve chordae tendineae. J. Biomed. Mater. Res. A, 2004, vol. 69, pp. 26-39.

14. Moreira R. et al. TexMi - Development of Tissue-Engineered Textile-Reinforced Mitral Valve Prosthesis. Tissue Eng. Part C. Methods, 2014, vol. 20, no. 9, pp.741-748.

15. Badylak S. F. et al. The use of xenogeneic small intestinal submucosa as a biomaterial for Achille's tendon repair in a dog model. J. Biomed. Mater. Res., 1995, vol.29, no. 8, pp.977-985.

16. Schoen F. J., Levy R. J. Calcification of tissue heart valve substitutes: Progress toward understanding and prevention. Ann. Thorac. Surg., 2005, vol.79, pp. 1072-1080.

17. Gilbert T.W. et al. Collagen fiber alignment and biaxial mechanical behavior of porcine urinary bladder derived extracellular matrix. Biomaterials, 2008, vol.29, no. 36, pp. 4775-4782.

18. Hodde J. et al. Effects of sterilization on an extracellular matrix scaffold: Part I. Composition and matrix architecture. J. Mater. Sci. Mater. Med., 2007, vol. 18, no. 4, pp.537-543.

19. Dong X. et al. RGD-modified acellular bovine pericardium as a bioprosthetic scaffold for tissue engineering. J. Mater. Sci. Mater. Med., 2009, vol. 20, no. 11, pp. 2327-2336.

20. Reing J.E. et al. The effects of processing methods upon mechanical and biologic properties of porcine dermal extracellular matrix scaffolds. Biomaterials, 2010, vol.31, no. 33, pp. 8626-8633.

21. Gorschewsky O. et al. Quantitative analysis of biochemical characteristics of bone-patellar tendonbone allografts. Biomed. Mater. Eng., 2005, vol. 15, no. 6, pp. 403-411.

22. Cox B., Emili A. Tissue subcellular fractionation and protein extraction for use in mass-spectrometrybased proteomics. Nat. Protoc., 2006, vol. 1, no. 4, pp. 1872-1878.

23. Xu C. C., Chan R. W., Tirunagari N. A Biodegradable, Acellular Xenogeneic Scaffold for. Tissue Eng., 2007, vol. 13, no. 3, pp. 551-566.

24. Giusti S. et al. An improved method to obtain a soluble nuclear fraction from embryonic brain tissue. Neurochem. Res., 2009, vol.34, no. 11, pp.2022-2029.

25. Chen R.-N. et al. Process development of an acellular dermal matrix (ADM) for biomedical applications. Biomaterials, 2004, vol.25, no. 13, pp. 2679-2686.

26. Nakayama K. H. et al. Decellularized rhesus monkey kidney as a three-dimensional scaffold for renal tissue engineering. Tissue Eng. Part A, 2010, vol. 16, no. 7, pp. 2207-2216.

27. Wong M.L. et al. The role of protein solubilization in antigen removal from xenogeneic tissue for heart valve tissue engineering. Biomaterials, 2011, vol. 32, pp. 8129-8138.

28. Rieder E. et al. Decellularization protocols of porcine heart valves differ importantly in efficiency of cell removal and susceptibility of the matrix to recellularization with human vascular cells. J. Thorac. Cardiovasc. Surg., 2004, vol. 127, no. 2, pp. 399-405.

29. Cebotari S. et al. Detergent decellularization of heart valves for tissue engineering: Toxicological effects of residual detergents on human endothelial cells. Artif. Organs, 2010, vol.34, no. 3, pp. 206-210.

30. Methe K. et al. An Alternative Approach to Decellularize Whole Porcine Heart. Biores. Open Access, 2014, vol.3, no. 6, pp. 327-338.

31. Meyer S.R. et al. Comparison of aortic valve allograft decellularization techniques in the rat. J. Biomed. Mater. Res. - Part A, 2006, vol.79, no. 2, pp. 254-262.

32. Lumpkins S.B., Pierre N., McFetridge P.S. A mechanical evaluation of three decellularization methods in the design of a xenogeneic scaffold for tissue engineering the temporomandibular joint disc. Acta Biomater., 2008, vol. 4, no. 4, pp.808-816.

33. Courtman D.W. et al. Development of a pericardial acellular matrix biomaterial: biochemical and mechanical effects of cell extraction. J. Biomed. Mater. Res., 1994, vol. 28, no. 6, pp.655-666.

34. Kasimir M. T. et al. Comparison of different decellularization procedures of porcine heart valves. Int. J. Artif. Organs, 2003, vol. 26, no. 5, pp. 421-427.

35. Petersen T.H. et al. Tissue-engineered lungs for in vivo implantation. Science, 2010, vol.329, no. 5991, pp. 538-541.

36. Du L. et al. Histological evaluation and biomechanical characterisation of an acellular porcine cornea scaffold. Br. J. Ophthalmol., 2011, vol. 95, no. 3, pp.410-414.

37. Gui L. et al. Novel utilization of serum in tissue decellularization. Tissue Eng. Part C. Methods, 2010, vol. 16, no. 2, pp. 173-184.

38. Booth C. et al. Tissue engineering of cardiac valve prostheses I: development and histological characterization of an acellular porcine scaffold. J. Heart Valve Dis., 2002, vol. 11, no. 4, pp. 457-462.

39. Caamaño $S$. et al. Does sodium dodecyl sulfate wash out of detergent-treated bovine pericardium at cytotoxic concentrations? J. Heart Valve Dis., 2009, vol. 18, no. 12, pp. 101-105.

40. Prasertsung I. et al. Development of acellular dermis from porcine skin using periodic pressurized technique. J. Biomed. Mater. Res. - Part B Appl. Biomater., 2008, vol. 85, no. 1, pp. 210-219. 
41. Levy R. J. et al. Inhibition of cusp and aortic wall calcification in ethanol- and aluminum-treated bioprosthetic heart valves in sheep: background, mechanisms, and synergism. J. Heart Valve Dis., 2003, vol. 12, no. 2, pp. 209-216; discussion 216.

42. Dunmore-Buyze J. et al. A Comparison of Macroscopic Lipid Content within Porcine Pulmonary and Aortic Valves. J. Thorac. Cardiovasc. Surg., 1995, vol. 110, no. 6, pp. 1756-1761.

43. Flynn L.E. The use of decellularized adipose tissue to provide an inductive microenvironment for the adipogenic differentiation of human adipose-derived stem cells. Biomaterials, 2010, vol.31, no. 17, pp. 4715-4724.

44. Brown B. N. et al. Comparison of three methods for the derivation of a biologic scaffold composed of adipose tissue extracellular matrix. Tissue Eng. Part C. Methods, 2011, vol. 17, no. 4, pp.411-421.

45. Cole M. B. Alteration of cartilage matrix morphology with histological processing. J. Microsc., 1984, vol. 133, no. Pt 2, pp. 129-140. 61.

46. Jamur M. C., Oliver C. Cell fixatives for immunostaining. Methods Mol. Biol., 2010, vol. 588, pp. 55-

47. Crapo P.M., Gilbert T.W., Badylak S. F. An overview of tissue and whole organ decellularization processes. Biomaterials, 2011, vol. 32, no. 12, pp. 3233-3243.

48. Yang M. et al. Favorable effects of the detergent and enzyme extraction method for preparing decellularized bovine pericardium scaffold for tissue engineered heart valves. J. Biomed. Mater. Res. - Part B Appl. Biomater., 2009, vol.91, no. 1, pp.354-361.

49. Waldrop F. S. et al. Histochemical investigations of different types of collagen. Acta Histochem. Suppl., 1980, vol.21, pp. 23-31.

50. Yang B. et al. Development of a porcine bladder acellular matrix with well-preserved extracellular bioactive factors for tissue engineering. Tissue Eng. Part C. Methods, 2010, vol. 16, no. 5, pp. 1201-1211.

51. Hopkinson A. et al. Optimization of amniotic membrane (AM) denuding for tissue engineering. Tissue Eng. Part C. Methods, 2008, vol. 14, no. 4, pp.371-381.

52. Hilfiker A. et al. Reduction of xeno-antigens in porcine pulmonary heart valves by decellularization and glycolytic enzymatic treatment. Xenotransplantation, 2014, vol.21, no. 2, pp. 190-190.

53. Klebe R. J. Isolation of a collagen-dependent cell attachment factor. Nature, 1974, vol. 250, no. 463, pp. $248-251$.

54. Maurer P., Hohenester E. Structural and functional aspects of calcium binding in extracellular matrix proteins. Matrix Biol., 1997, vol. 15, no. 8-9, pp. 569-580; discussion 581.

55. Tudorache I. et al. Tissue engineering of heart valves: biomechanical and morphological properties of decellularized heart valves. J. Heart Valve Dis., 2007, vol. 16, pp. 567-573; discussion 574.

56. Wainwright J.M. et al. Preparation of cardiac extracellular matrix from an intact porcine heart. Tissue Eng. Part C. Methods, 2010, vol. 16, no. 3, pp. 525-532.

57. Lehr E.J. et al. Decellularization reduces immunogenicity of sheep pulmonary artery vascular patches. J. Thorac. Cardiovasc. Surg. The American Association for Thoracic Surgery, 2011, vol. 141, no. 4, pp. 1056-1062.

58. Gillies A.R. et al. Method for decellularizing skeletal muscle without detergents or proteolytic enzymes. Tissue Eng. Part C. Methods, 2011, vol. 17, no. 4, pp. 383-389.

59. Patel N. et al. Strategies to recover proteins from ocular tissues for proteomics. Proteomics, 2008, vol. 8, no. 5, pp. 1055-1070.

60. Cortiella J. et al. Influence of acellular natural lung matrix on murine embryonic stem cell differentiation and tissue formation. Tissue Eng. Part A, 2010, vol. 16, no. 8, pp. 2565-2580.

61. Lee R. C. Cell injury by electric forces. Ann. N. Y. Acad. Sci., 2005, vol. 1066, pp. 85-91.

62. Phillips M., Maor E., Rubinsky B. Nonthermal irreversible electroporation for tissue decellularization. J. Biomech. Eng., 2010, vol. 132, no. 9, pp. 091003.

63. Rieder E. et al. Tissue engineering of heart valves: Decellularized porcine and human valve scaffolds differ importantly in residual potential to attract monocytic cells. Circulation, 2005, vol.111, no. 21, pp. 2792-2797.

64. Simon P. et al. Early failure of the tissue engineered porcine heart valve SYNERGRAFT in pediatric patients. Eur. J. Cardio-thoracic Surg., 2003, vol. 23, pp. 1002-1006.

65. Yacoub M.N. et al. Fourteen-Year Experinence with Homovital Homografts for Aortic Valve Replacement. J. Thorac. Cardiovasc. Surg., 1995.

66. Macher B. A., Galili U. The Galalpha1,3Galbeta1,4GlcNAc-R (alpha-Gal) epitope: a carbohydrate of unique evolution and clinical relevance. Biochim. Biophys. Acta, 2008, vol. 1780, no. 2, pp. 75-88.

67. Wong M. L. et al. Stepwise solubilization-based antigen removal for xenogeneic scaffold generation in tissue engineering. Acta Biomater. Acta Materialia Inc., 2013, vol. 9, no. 5, pp. 6492-6501. 
68. Cicha I. et al. Early obstruction of decellularized xenogenic valves in pediatric patients: involvement of inflammatory and fibroproliferative processes. Cardiovasc. Pathol., 2011, vol. 20, no. 4, pp. $222-231$.

69. Rüffer A. et al. Early failure of xenogenous de-cellularised pulmonary valve conduits - a word of caution! Eur. J. Cardio-thoracic Surg., 2010, vol.38, no. 1, pp. 78-85.

70. Perri G. et al. Early and late failure of tissue-engineered pulmonary valve conduits used for right ventricular outflow tract reconstruction in patients with congenital heart disease. Eur. J. Cardio-thoracic Surg., 2012, vol.41, no. 6, pp. 1320-1325.

71. Da Costa F. D. a et al. The early and midterm function of decellularized aortic valve allografts. Ann. Thorac. Surg. Elsevier Inc., 2010, vol. 90, no. 6, pp. 1854-1860.

72. Cebotari S. et al. Use of fresh decellularized allografts for pulmonary valve replacement may reduce the reoperation rate in children and young adults: Early report. Circulation, 2011, vol. 124.

73. Iablonskii P. et al. Tissue-engineered mitral valve: morphology and biomechanics. Interact. Cardiovasc. Thorac. Surg., 2015, pp. 1-8.

Для цитирования: Яблонский П.П., Чеботарь С., Тудорахе И., Хаверих А. Тканевые матрицы клапанов сердца: состояние проблемы и перспективы // Вестник Санкт-Петербургского университета. Серия 11. Медицина. 2016. Вып. 2. С. 51-61. DOI: 10.21638/11701/spbu11.2016.206

For citation: Iablonskii P. P., Cebotari S., Tudorache I., Haverich A. Heart Valve Matrices: State of the Art and Perspectives. Vestnik of Saint Petersburg University. Series 11. Medicine, 2016, issue 2, pp. 51-61. DOI: $10.21638 / 11701 /$ spbu11.2016.206

Статья поступила в редакцию 5 мая 2016 г.

Контактная информация:

Яблонский Павел Петрович — ассистент; pavel.yablonski@gmail.com

Чеботарь Сергей - приват-доцент, доктор медицинских наук; cebotari.serghei@mh-hannover.de Тудорахе Игорь - доктор медицинских наук; tudorache.igor@mh-hannover.de

Хаверих Аксель - профессор, доктор медицинских наук; haverich.axel@mh-hannover.de

Iablonskii Pavel P. — resident; pavel.yablonski@gmail.com

Cebotari Serghei — privat-docent, MD; cebotari.serghei@mh-hannover.de

Tudorache Igor — MD; tudorache.igor@mh-hannover.de

Haverich Axel — Professor, MD; haverich.axel@mh-hannover.de 